\title{
ENTRE A CASA E A ESCOLA: SOBRE PERCURSOS E VIAGENS!
}

DANIELLY SAMARA BESEN

Universidade do Estado de Santa Catarina

VERA LUCIA GASPAR DA SILVA

Universidade do Estado de Santa Catarina

\section{EMERSON CORREIA DA SILVA}

Faculdade Cesusc

RESUMO

O objetivo deste artigo constitui-se em destacar registros memorialísticos de professoras e professores que atuaram no ensino primário catarinense (1950 a 1980), com foco nas passagens em que rememoram idas e vindas para chegarem à escola. Os relatos que são aqui analisados foram registrados por professoras, que atuaram na rede estadual de ensino de Santa Catarina, e discorrem sobre a trajetória escolar, a carreira profissional e as experiências pedagógicas. De um universo bem mais amplo, foram escolhidos 137 registros de professoras que compartilham suas memórias, ora como alunas e ora como professoras. Entre as lembranças partilhadas, estão as dificuldades que encontraram para estudar e o deslocamento da casa até a escola e vice-versa, que aparece com grande riqueza de detalhes, desvelando aspectos do cotidiano escolar que têm sido pouco socializados. Como resultado das análises, foi possivel narrar, com base em "registros memorialísticos", a partir do ponto de vista das professoras, percursos que fizeram e suas vivências como veiculadoras e portadoras de conhecimentos que são apropriados nas escolas normais e nos institutos de formação. Revelam também que o que caracteriza uma viagem não é apenas a distância percorrida, mas as vicissitudes encontradas no percurso.

Palavras-chave: Acesso a escolarização. Viagens. Percursos escolares.

\section{ABSTRACT BETWEEN HOME AND SCHOOL: A STUDY CONCERNING PATHWAYS AND JOURNEYS!}

This article aims at highlighting memorial records of teachers working in the primary school of the Brazilian State of Santa Catarina (1950 to 1980), focusing on the passages where they narrate their comings 
and goings to get to school. These testimonials were recorded by teachers who work at the State of Santa Catarina education network. Through these records, the teachers talked about their pathways to get to school, their professional careers, and pedagogical experiences. We managed to pick 137 records out of a much broader universe of people who share their memories both as students and as teachers. Among these shared memories are the difficulties these teachers were faced with while trying to study. The teachers narrate their way from home to school and vice-versa is in details, thus revealing seldom-socialized aspects of their daily routines. From the results, it was possible to understand, based on the "memorial records" of the teachers, the paths they have made and the lives they lived, acting as vehicles and carriers of knowledge gathered in common schools and educational institutions. They also reveal that, what makes a journey is not only the distance traveled, but, also, the changes faced during this process.

Keywords: Access to schooling. Journeys. School paths.

\section{ENTRE LA CASA Y LA ESCUELA: iSOBRE LOS}

\section{RECORRIDOS Y LOS VIAJES!}

El propósito de este artículo radica en destacar los registros de memorias de maestros y maestras que trabajaron en la enseñanza primaria de Santa Catarina (1950-1980), centrándose en pasajes en los que recuerdan sus idas y venidas para llegar a la escuela. Las narraciones que se analizan aquí fueron registradas por maestras que trabajaron en la red estatal de enseñanza de Santa Catarina. En ellas discurren sobre la trayectoria escolar, la carrera profesional y las experiencias pedagógicas. De un universo mucho más amplio, se eligieron 137 registros de maestras que comparten sus memorias a veces como alumnas y otras como docentes. Entre los recuerdos compartidos están las dificultades que enfrentaron para estudiar, el desplazamiento desde su casa hasta la escuela y viceversa aparece en una gran riqueza de detalles, revelando aspectos de la vida escolar diaria que han sido poco socializados. Como resultado de los análisis fue posible narrar, en base a los "registros de las memorias", desde el punto de vista de las maestras, los recorridos que hicieron y las vivencias como trasmisoras y portadoras de conocimientos apropiados en las escuelas normales e institutos de formación. También revelan que lo que caracteriza un viaje no es sólo la distancia recorrida, sino las vicisitudes encontradas en el camino.

Palabras clave: Acceso a la escolarización. Viajes. Recorridos escolares. 
Neste texto, fizemos a escolha de destacar registros memorialísticos de professoras e professores que atuaram no ensino primário catarinense (1950 a 1980), os quais, originalmente, tomaram a forma de respostas a questionários, em passagens nas quais esses docentes rememoram idas e vindas para chegarem a escola. Embora na bibliografia da área seja mais recorrente explorar as "viagens pedagógicas", sejam aquelas realizadas dentro de um país, sejam as que envolvem visitas ao estrangeiro, optamos por considerar os deslocamentos entre a casa e a escola também como viagens. A aposta é que as experiências vivenciadas nestes deslocamentos também formam os docentes: o que veem, o que fazem, o que experimentam, como experimentam... deslocamentos fisicos e metafóricos, ${ }^{2}$ que se mesclam à formação e ao exercício da docência, já no espaço da escola.

As viagens das quais trataremos se materializam em distâncias percorridas, em mudanças de um município para outro, na vinda do interior para a capital, do centro da cidade para a zona rural, em deslocamentos diários dentro de uma mesma cidade. A exemplo do que ocorre com o professorado, o trajeto que os estudantes percorrem da casa até a escola é também um componente formativo, haja vista que aquilo que se encontra no caminho - os medos, desafios, adversidades, o frio, o calor, os insetos, as árvores, as frutas, os amigos -, também compõe o mosaico das lembranças sobre a escola e os processos de aprendizagem.

1 Exemplo deste tipo de produção é o livro Viagens pedagógicas, organizado por Ana Chrystina Venancio Mignot e José Gonçalves Gondra, publicado pela Editora Cortez, em 2007.

2 Aqui inspiramos-nos em reflexões de Denice Catani, registradas, a modo de Prefácio, no livro Viajar é inventar o futuro: narrativas de formação e o ideário educacional brasileiro nos diários e relatório de Anísio Teixeira em viagem à Europa e aos Estados Unidos (1925-1927), de autoria de Silmara de Fatima Cardoso e Dislane Zerbinatti Moraes, publicado em 2014 pela Paco Editorial.
Para narrar os deslocamentos e viagens caracterizadas acima, dividimos o texto em três partes: Das fontes e dos modos de operá-las; Percursos e Travessias: do quanto andavam, e Viagens: das mudanças de cidade. Na primeira, as fontes com as quais trabalhamos serão caracterizadas, de modo a situar o leitor no universo com o qual operamos. Na segunda, tratamos dos trajetos entre a casa e a escola, com suas dificuldades, distâncias e meios de locomoção. Na terceira parte, as atenções voltam-se para as mudanças de cidade e as acomodações.

As adversidades enfrentadas para se chegar à escola podem render boas histórias que avôs e avós contam, lembrando os tempos de criança. Ainda hoje, por vezes, estes deslocamentos são abordados em noticiários quase como curiosidade, outras em tons de preocupação ou indignação. Diariamente, milhares de crianças submetem-se - e muitas continuam se submetendo - a longas jornadas para chegar à escola e cumprir um preceito legal, que se estendeu com força pelo mundo, particularmente a partir da segunda metade do século XIX, a obrigatoriedade escolar para a infância. No caso das experiências aqui tomadas como material empírico, os percursos, marcados por longas distâncias, podiam ser percorridos a pé, em canoas, de bicicleta ou de carroça. Mas como era este trajeto até o local de trabalho? Quais eram as condições para quem se mudava, para longe de seu "lugar de origem", para lecionar? Perguntas como estas guiaram nosso olhar na elaboração do presente artigo. Para além de uma análise sobre o acesso à escola e à distribuição do edifício escolar no território catarinense, almejamos abordar experiências vivenciadas nos deslocamentos, entre a casa e a escola, compondo um quadro que retrate parte desta movimentação e sua implicação na escolarização e na docência. 


\section{Das fontes e dos modos de operá-las}

Os relatos que serão aqui analisados foram registrados por professoras que atuaram na rede estadual de ensino de Santa Catarina, e que os fizeram, quando já estavam aposentadas. Neles, discorrem sobre a trajetória escolar, a carreira profissional e suas experiências pedagógicas. De um universo bem mais amplo, foram escolhidos 137 registros de professoras $^{3}$ que atuaram entre os anos de 1950 a 1980, no ensino primário estadual, e que, como já anunciado, compartilham suas memórias ora como alunas e ora como professoras. ${ }^{4}$ Entre as lembranças partilhadas estão as dificuldades que encontraram para estudar e o deslocamento da casa até a escola e vice-versa, tanto como alunas como enquanto docentes, que aparecem com grande riqueza de detalhes, desvelando aspectos do cotidiano escolar que têm sido pouco socializados.

0 material que aqui nos serve de fonte foi retirado de uma amostra de respostas registradas em questionários que hoje integram o acervo do projeto de pesquisa "Memória Docente: os impactos do movimento de escolarização em Santa Catarina sobre a carreira docente, as identidades profissionais e o trabalho pedagógico de professores da rede estadual de ensino". Tal pesquisa, levada a efeito entre 2009 e 2012 no interior do Grupo de

3 Desses, $92 \%$ são mulheres e $8 \%$ são homens. Quase $80 \%$ dos docentes eram ou já haviam sido casados e $13 \%$ eram solteiros, no momento em que registraram suas respostas; o restante não respondeu aos itens relacionados a estes aspectos. Assim, por constituírem a maior parte da amostra, fizemos a escolha pela derivação feminina.

4 As respostas atribuídas a estes questionários e o produto de entrevistas a eles relacionadas têm sido objeto de análise de vários integrantes do Grupo de Pesquisa, que empreendeu a tarefa de aplicar, reunir e sistematizar este acervo, que, atualmente, conta com cerca de 1.000 questionários respondidos e uma significativa amostra de entrevistas.
Pesquisa Ensino e Formação de Educadores em Santa Catarina - GPFESC ${ }^{5}$ se propunha, por intermédio da aplicação de questionários e da realização de entrevistas, recuperar, registrar e analisar parte da memória docente do magistério público estadual. Nossa amostra é formada por respostas registradas em questionários que foram aplicados nos primeiros anos da pesquisa e que foram objeto de estudo da dissertação (BESEN, 2011).

Conhecer aspectos das trajetórias de vida de protagonistas da cena escolar é um caminho privilegiado para melhor compreendê-la, mas, como em qualquer abordagem, essa também apresenta limites e exige vigilância. Como nos alertam Stephanou e Bastos (2011), a memória é como um caleidoscópio no qual se intercruzam múltiplos fragmentos para compor uma imagem. Os fragmentos aqui referem-se a experiências, sejam as de escolarização do tempo da infância, sejam aquelas rememoradas com base na atuação profissional, registradas no material analisado. Vale observar que, no efeito próprio do caleidoscópio, por vezes, as informações se misturam, sendo dificil precisar as experiências às quais os professores estão se referindo, se as de estudantes ou as de professores. Neide Fiori (2010) é uma das autoras que faz um alerta sobre o uso de memórias. Embora no texto aqui reportado ela se refira à história oral, entendemos que as observações continuam oportunas, mesmo para o caso de registros escritos. Segundo a autora, não se pode ne-

50 referido projeto foi coordenado por lone Ribeiro Valle com desdobramentos, até o momento (2017) em mais duas iniciativas: Projetos de Pesquisa "Memória Docente e Justiça Escolar: Os movimentos de escolarização e de profissionalização do magistério em Santa Catarina", desenvolvido entre 2012 e 2015, e "Educação Escolar, Justiça Social e Memória Docente: As múltiplas faces das desigualdades escolares em Santa Catarina" que teve início em 2015 e encontra-se em desenvolvimento, os dois últimos também coordenados por lone valle. As autoras deste artigo integram a equipe de pesquisadores do GPFESC. 
gar o interesse de colocar em evidência trajetórias individuais que dão um colorido especial às análises do passado, mas também não se pode negligenciar que tais relatos são incapazes de expressar todos os detalhes e nuanças da experiência vivida, pois é preciso estar atento às fraquezas da memória e a sua tendência para a lenda e o mito. Levando em conta este alerta e inspirados pelas reflexões de Denice Catani (2014), tratamos os relatos em articulação com a imagem da travessia, como um modo de deslocamento de um estado a outro de desenvolvimento, e sua relação, quase mítica, de desafios, distâncias e dificuldades com os meios de transporte, relatados pelas docentes. Catani afirma que:

Professores, mentores, educadores acompanham a viagem de seus educandos até algum ponto de suas trajetórias e retornam solitários ao seu ponto de partida, ao final de um ano letivo, de um semestre, de um período maior ou menor ou de um estágio da vida que os reuniu. Tais são alguns dos sentidos dos quais as menções à viagem se impregnam e abrem passagem para inúmeras e frutíferas aproximações entre o processo educativo, o trabalho docente e a ideia de deslocamento. (CATANI, 2014, p. 7)

Esses períodos são muito vivos nas memórias registradas no material que aqui nos serve de base, o que pôde ser percebido ao longo da pesquisa. No trato com este material, compartilhamos com Cardoso e Zerbinatti Moraes (2014, p. 19), que advertem que "o pesquisador deve fazer uso dessas narrativas sabendo que elas são construídas por sujeitos históricos - cuja formação, intenção, visão de mundo e objetivo podem influir decisivamente na tessitura dos textos". Para as autoras, o caminho de pesquisa para o tratamento desses materiais passa por sua construção como fonte. Em nosso caso, buscamos coletar os relatos e descrevê-los neste contexto, conectando-os uns aos outros, registrando sua origem e os modos como operamos.

\section{Percursos e Travessias: do quanto andavam}

Poucos recursos na agricultura - distância de $30 \mathrm{~km}$ para estudar à noite com condição muito precária, nos dias de chuva tínhamos que usar uma sombrinha dentro da condução senão nos molhávamos.

$\left(\right.$ ALVES, 2010) ${ }^{6}$

As adversidades encontradas para se deslocar da casa até a escola faziam com que as alunas e professoras andassem muitos quilômetros a pé. A grande distância, entre a residência e a escola, fazia com que algumas percorressem até 30 quilômetros a pé, diariamente. Para outras, foi preciso sair de casa: "saí de casa e fiquei interna por seis anos para estudar, quando voltei continuei estudando, andava três quilômetros para pegar ônibus e ir até o colégio" (ROSA, 2010). Em outro relato, o morar longe da escola implicava caminhar sete quilômetros, após um longo dia de trabalho: "morava a sete quilômetros longe da escola e era muito pobre. Trabalhava o dia inteiro" (PROENÇA, 2011). A falta de materiais escolares juntava-se à falta de agasalhos e calçados, à fome e à discriminação, por ser filha de colono.7 Neste quadro de adversidades, era necessário fazer o percurso enfrentando sol e chuva, em uma distância que poderia variar entre seis a trinta quilômetros da escola. Aspectos como esses, presentes nas narrativas, registram as agruras e as vicissitudes das professoras, nos deslocamentos entre a casa a escola, seja enquanto alunas ou já na condição de professoras. Mas há também elementos nostálgicos, como o que se pode ler a seguir, fruto das rememora-

6 Os nomes mencionados são fictícios, a fim de preservar a identidade dos sujeitos que responderam os questionários.

7 Tal afirmação é inspirada no relado da professora Beatriz Cavalcante (2010), pois, segunda ela, a falta de "uniforme, de livros, de calçado, a distância para chegar à escola, sem lanche, com frio e descalço [sic]", eram suas maiores dificuldades para estudar. 
ções da professora Elisa Pereira: “lembro que quando chegava à escola (eu ia de bicicleta) vinham todos correndo me encontrar, faziam até o caminho enfeitado com flores... nossa, minha carreira foi maravilhosa" (PEREIRA, 2010).

Nem todas percorriam o longo trajeto até a escola a pé; a distância era vencida também com o uso de diferentes meios de transporte. Para algumas era preciso atravessar "um rio de canoa todos os dias" (GUIMARÃES, 2010) ou ainda viajar de ônibus, para outros municípios, com passagem cara, às vezes enfrentando "ônibus velhos que viviam quebrando, muitas vezes chegávamos de madrugada em casa" (MONTEIRO, 2010); outras se deslocavam de dez a doze quilômetros em estrada de chão ruim, de carroça ou bicicleta. Assim, a ausência de transporte escolar regular, aliada ao fato de muitos morarem no interior, obrigava o deslocamento a pé, em bicicletas, com canoas, ou ainda com o uso de charretes.

Aliás, a distância entre o lar e a escola, as dificuldades de locomoção e a situação financeira das famílias são os três principais problemas apontados nos relatos, no tocante ao acesso e à própria escolarização; são fatores atravessados por aspectos sociais e econômicos que merecem ser situados. As docentes que assumem aqui o papel de sujeitos são nascidas predominantemente nas décadas de 1940 e 1950, tendo a maioria começado seus estudos em escolas isoladas, ${ }^{8}$ na mesma modalidade de escola na qual grande parte iniciou o exercício no magistério. ${ }^{9}$

8 Dos 137 professores aqui envolvidos, 51\% realizaram o ensino primário em escolas isoladas e $19 \%$ em escolas reunidas. O questionário não contemplou, no seu quadro de perguntas, outras opções, tais como: grupos escolares e ensino complementar. Apesar disso, localizamos em três deles a observação de ter cursado o ensino complementar e, em outros dois, a observação "grupo escolar" ao lado do ano de conclusão do ensino fundamental.

$932 \%$ dos professores que compõem este estudo iniciaram suas atividades profissionais como membros do magistério estadual, em escolas isoladas. Sobre esta modalidade de escola, sugerimos a leitura da dissertação intitulada "Um mal necessário: as escolas
Filhas de agricultores, donas de casa, comerciantes e operários, profissões que em geral indiciam famílias de baixo capital cultural e escolar, é possivel inferir que a expansão tardia das redes públicas, estaduais e municipais, contribuiu para este quadro, particularmente no que respeita ao nivel de escolaridade mais baixo para os pais em relação àquele conquistado pelas filhas professoras. Enquanto a maioria dos pais teve um nível de escolaridade limitado ao ensino primário, com pouca qualificação, os dados registrados nos questionários apresentam sujeitos que já são diplomados nos níveis médio e/ou superior, permitindo-lhes obter diplomas de niveis mais elevados, e exercerem uma atividade profissional melhor qualificada. São sujeitos oriundos especialmente do espaço rural ou, no mínimo, daquele periférico às regiões mais urbanizadas. Considerando os sujeitos desta amostra, duas regiões que compõem a atual organização administrativa do Estado são predominantes como lugar de origem: a do Vale do Itajaí e a Grande Florianópolis, que inclui a capital do Estado. A título de exemplo, segundo dados do IBGE (2017), nos anos de 1950, a capital contava com 67.630 habitantes: $73,5 \%$ da população acima de dez anos sabiam ler e escrever. No que se refere à estrutura, Florianópolis contava com 226 logradouros, desses 155 não eram pavimentados, 103 não tinham iluminação pública e 145 contavam com água canalizada. É possível identificar, nos relatos, alusão às condições estruturais do Estado:10 “[...] estudar à noite e trabalhar o dia inteiro, com estrada precária e sem iluminação" (RECH, 2010).

A distância de zonas mais urbanizadas e as frágeis condições econômicas de uma família ou região vincula-se quase que diretamente à ausência de meios de transporte: "devido à

isoladas no projeto republicano (Santa Catarina, 19111928)", de autoria de Luiza Pinheiro Ferber, defendida em 2015 no PPGE/UDESC.

10 Importante lembrar que, no quadro nacional, Santa Catarina figura com indicadores bastante positivos. 
distância, não tinha transporte muitas vezes. Não tinha condições de comprar livros para pesquisa, pois dependia exclusivamente de meus pais" (MARQUES, 2010). O deslocamento das crianças e professoras, particularmente nas zonas rurais mais afastadas, só começou a receber atenção mais efetiva, nas décadas finais do século XX, com a implementação das políticas de transporte escolar. A necessidade de oferta deste tipo de transporte, no Brasil, está registrada na Constituição de 1988, em item referente aos programas suplementares, como forma de assegurar a frequência escolar obrigatória. Apesar do debate acerca da necessidade de ampliar as oportunidades de acesso à escola pública, notadamente no meio rural, ser anterior à promulgação da Constituição, ${ }^{11}$ é apenas em 1994, com a publicação da Portaria no 955, de 21 de junho do mesmo ano, que se cria o Programa Nacional de Transporte Escolar (PNTE). Esse programa objetivou contribuir financeiramente com municípios e organizações não governamentais, para a aquisição de veículos novos, destinados ao transporte dos alunos da rede pública do Ensino Fundamental, residentes na zona rural, e das escolas que atendiam alunos com necessidades especiais. A partir de 2004, a política é modificada e são criados dois novos programas: o Programa Nacional de Apoio ao Transporte Escolar (PNATE) e o Caminho da Escola. ${ }^{12}$ A ação do transporte

11 Localizamos a Lei no 5.684, de 09 de maio de 1980, que discorre sobre o serviço público de transporte rodoviário intermunicipal em Santa Catarina. Essa lei concede, ao professor público estadual, o direito de deslocamento gratuito no trajeto escola-casa e viceversa. Os alunos de 1ㅇ, 20 e 3 o graus, devidamente matriculados, teriam direito a um desconto de $50 \%$, mediante a aquisição de passe mensal, durante o período escolar, no trajeto escola-casa e vice-versa.

12 O Pnate foi criado em 2004, com o objetivo de garantir o acesso e a permanência dos estudantes residentes em área rural ao Ensino Fundamental, em escolas públicas. Em 2009, o Programa é ampliado para os estudantes da Educação Infantil e do Ensino Médio, contemplando assim toda a educação básica. A transferência de recursos do governo federal aos Estados, Distrito Federal e municípios considera o número de alunos da zona rural transportados e tem como base escolar visa garantir o direito à educação por meio do acesso e da frequência à instituição escolar, para aqueles que residem em áreas rurais e, atualmente, é realizado por meio de ônibus, lanchas e bicicletas.

Além das adversidades quanto às formas para se chegar a escola, ainda não superadas, não se pode deixar de considerar que, desde os anos de 1940 - e citamos apenas o período com o qual se está trabalhando aqui -, um conjunto de ações administrativas reorganiza o mapa de criação e manutenção das escolas. A despeito das iniciativas de democratização do acesso, nos últimos anos, tem sido alarmante o número de unidades fechadas, sob as justificativas do baixo número de matrículas e da racionalização dos serviços. Na retórica do Estado - e aqui temos por referência o poder público de Santa Catarina -, estas crianças passariam a frequentar escolas em outras regiões; na prática, muitos deixam de ter acesso à escola, ferindo o princípio quase universal de acesso.

Alia-se às dificuldades de acesso, a falta de recursos financeiros "para compra de material escolar, livros, pois na época o governo não fornecia, tudo era comprado, tudo era mais dificil" (FLUSSER, 2010). Para outras, só foi

o quantitativo de alunos da zona rural informados no Censo Escolar do Inep, assim como a posição do município na linha da pobreza. Os recursos devem ser utilizados para custear as despesas do uso do veículo. Em 2014, o Pnate atendeu a 4.547.690 alunos. O Programa Caminho da Escola (2009) foi instituído em 2007, a fim de padronizar, renovar e ampliar a frota de veículos do transporte escolar. A aquisição dos veículos deve ocorrer por meio de pregão eletrônico, com registro de preço nacional, sendo realizada pelo FNDE (Fundo Nacional de Desenvolvimento da Educação). Os veículos contêm especificações próprias e adequadas à trafegabilidade nas vias das áreas rurais. Em 2009, o FNDE firmou uma parceria com a Marinha do Brasil, para a construção de 674 lanchas escolares para o transporte de crianças ribeirinhas. Em 2010, o Programa é novamente ampliado, após uma série de estudos realizados pelo FNDE indicar que muitas crianças percorriam a pé, diariamente, de três a 15 quilômetros para chegar à escola ou ao ponto onde passava o ônibus escolar. A bicicleta foi apontada como alternativa, e passa a fazer parte do rol de veículos do programa. (MEC/ FNDE, 2017) 
possivel concluir parte da escolarização, graças a bolsas de estudos, como nos conta a professora Terezinha Nunes (2010): “a escola era particular, no curso ginasial ganhávamos uma porcentagem de bolsa, o restante era pago e éramos três irmãs".

Apesar das agruras, o "sonho de ser professora" instigou muitas a trilharem os caminhos da profissão. Por vezes, a relação entre muito trabalho e estudo, associada às dificuldades de toda ordem, são ambos fatores que faziam com que se sentissem verdadeiras "heroínas", o que era coroado particularmente a cada formatura de seus alunos. A questão da distância também coloca-se entre as razões que levaram à escolha do magistério como profissão. Muitos atribuem ao fato de ser a formação profissional ao alcance, sobretudo porque não tinham outras opções de cursos em suas cidades. Considerando o Estado de Santa Catarina, é nos anos de 1960 que a política educacional passou a privilegiar, de forma mais significativa, o acesso ao ginásio normal, nos municípios do interior, condicionando a frequência ao ingresso e à mobilidade, na carreira docente: muitos se sentiam "sem alternativa, [pois era] o único curso oferecido" (SENS, 2010) e "por ser o curso normal a única opção de continuar os estudos" (CONRADI, 2010). A falta de outros cursos de formação atrelada às dificuldades de se locomover a outro município, tais obstáculos faziam com que muitos nem pensassem em outra opção. Além disso, "era a melhor opção ao alcance financeiro da família" (CANDIDO, 2010).

Corroborando o indicado acima, de acordo com Auras (1998) e Schneider (2008), a ampliação da oferta do curso normal ginasial, em quase todos os municípios catarinenses, sobretudo no interior do Estado, que contava com uma crescente demanda, considerandose as exigências da Lei no 3.191 de 1963, que regulamentou as diretrizes da LDB/1961 no Es- tado, não concorreu apenas para formar professores. A ausência de outras instituições de ensino secundário, nos municípios do interior, fazia do ensino normal de 1o ciclo a única opção de escolarização dos egressos do ensino primário que desejavam dar continuidade aos estudos. Ainda segundo Auras (1998, p. 34), "tais cursos representavam uma opção barata [...] uma vez que além de funcionarem [...] nos prédios dos grupos escolares, aproveitavam de seu pessoal técnico e administrativo, além de utilizarem como docentes os próprios professores do curso primário". Para Schneider (2008, p. 122), a expansão do ensino normal de 1o ciclo "oportunizou a muitos jovens catarinenses o acesso ao ensino secundário, mas permaneceram as distinções entre a grande 'massa' que concluía o ciclo ginasial, e os poucos que conseguiam dar prosseguimento aos estudos".

Aparecem, também, aspectos relativos às instituições religiosas, seja pela concessão de bolsas de estudo ou porque era a formação oferecida, "no colégio das irmãs catequistas só tinha o curso do magistério, por esta razão me formei" (RIOS, 2010). Além disso, "estudar no colégio interno era a única oportunidade que os pais confiavam já que o colégio Pio $\mathrm{XII}^{13}$ era de boa reputação e respeitado na época, ficava próximo de casa e oferecia hospedagem" (SARDÁ, 2010).

Como indiciado nos dados com os quais operamos aqui, dentre os motivos que levaram essas professoras à escolha e à permanência na carreira docente, encontram-se elementos da política educacional catarinense, entrecruzados às suas condições socioeconômicas.

13 Escola situada na cidade de Rio do Oeste, região do Alto Vale do Itajaí/SC, fundada em 1960 pelas Irmãs Missionárias da Consolata, como Ginásio PIO XII, apenas para meninas. Em 1964, passa a ofertar o Curso Normal e a designar-se Colégio PIO XII. (Prefeitura Municipal de Rio do Oeste. Disponivel em: <http:// www.riodooeste.com.br/historia/?id=institu/album \& $p=1 \& r=2 \& i=6>$. Acesso em: 18 mar. 2017.) 
Pertencentes a camadas sociais menos favorecidas, em termos materiais, e pouco escolarizadas, a carreia docente normalmente é considerada a melhor, senão a única opção profissional, especialmente no caso das mulheres. Esse dado, de modo algum, diminui a importância das lutas que travaram para se estabelecerem profissionalmente, e ajuda a desmontar a crença no magistério como um caminho natural para constituírem-se professoras. ${ }^{14}$

\section{Viagens: das mudanças de cidade}

Sair da casa dos pais no interior e morar na casa de estranhos no centro, tendo que trabalhar e estudar, integra um rol de dificuldades apontadas pelas docentes: são dificuldades geográficas, econômicas e “interdições morais", agravadas pela quase ausência de pensões para estudantes. "Meus pais moravam no interior, vim para a cidade trabalhar como doméstica para sobreviver e poder estudar. [No Ensino Normal] continuei morando na casa dos outros, trabalhando como doméstica para concluir meus estudos e me formar professora" (MEYER, 2010).

A exemplo da experiência registrada entre os docentes ou aspirantes, as relações familiares parecem decisivas, quando se pretende dar prosseguimento aos estudos. Isto não significa que alguns não tenham enfrentado a falta de apoio dos pais para estudar: "Não tive apoio dos pais. Na época do ensino normal trabalhava e à noite estava cansada, com fiIha pequena" (KONS, 2010). Após o casamento, parece que as dificuldades aumentavam para algumas professoras; conciliar as atividades profissionais, maternas e a distância da escola não era tarefa fácil, como é possível observar

14 Sobre o tema, sugerimos a leitura do artigo "Profissão: Professora!", de autoria de Vera Lucia Gaspar da Silva, que integra o livro Feminização do magistério: vestígios do passado que marcam o presente. In: CAMPOS, Maria Christina Siqueira de Souza; GASPAR DA SILVA Vera Lúcia. (Orgs.). Bragança Paulista, SP: Editora da Universidade São Francisco, 2002. p. 95-121. nos registros a seguir: "pobre, casada, filhos para cuidar, lecionar e cuidar da casa" (GOMES, 2010); "deixar meus filhos com meu marido e minha mãe. Ficar a semana fora de casa" (SILVEIRA, 2010). Outro aspecto que se destaca, na análise dos dados, refere-se à discriminação às vezes de colegas, às vezes de professores, por serem filhas de colonos ou por virem do interior do Estado.

Como já indicamos antes, analisar aspectos das trajetórias como as que compõem este estudo exige que nos reportemos também, dentre outras questões, às políticas educacionais do período. Os anos de 1960 são marcados por ações que pretendem a modernização administrativa, política e econômica do Estado. A ideia do projeto nacional desenvolvimentista chega a Santa Catarina, no Governo de Celso Ramos (1961-1965), e se torna evidente na aprovação do I Plano de Metas do Governo (PLAMEG, 1961). Esse plano, aprovado em julho de 1961, tinha a intenção anunciada de impulsionar a industrialização catarinense e estabeleceu as metas básicas de governo, no intuito de superar um dos indicativos mais preocupantes dos diagnósticos, a carência de mão de obra qualificada, que era considerada uma das grandes responsáveis pela estagnação da economia do Estado.

No âmbito federal, no que se refere ao campo educacional, temos a aprovação da primeira Lei de Diretrizes e Bases da Educação Nacional, no ano de 1961 (Lei no 4.024, BRASIL, 1961). Conforme projetado nessa lei, no que concerne à formação docente, o ensino normal teria a finalidade de formar não somente professores, mas orientadores, supervisores e administradores escolares para atuarem no ensino primário. Esse nível de ensino estaria organizado em dois ciclos: o primeiro, a escola normal de grau ginasial, com, no mínimo, quatro séries anuais, em que seriam ministradas disciplinas de preparação pedagógica e expedido o diploma de 
regente de ensino primário. o segundo ciclo daria prosseguimento ao grau ginasial, em escola normal de grau colegial, e teria a duração de três séries anuais, essas escolas expediriam o diploma de professor primário. ${ }^{15}$

A operacionalização das diretrizes emanadas na LDB/1961, em Santa Catarina, deu-se pela Lei no 3.191 de 1963 na gestão de governo de Celso Ramos. Essa lei determinava que tanto os regentes de ensino primário quanto os professores normalistas estariam habilitados para o exercício do magistério. Segundo Auras (2002), ainda foram executadas no mandato de Celso Ramos, por intermédio do Gabinete de Planejamento do 1o PLAMEG, sob a forma de planos setoriais, as metas relacionadas à ampliação quantitativa da rede escolar e à disseminação do curso normal ginasial. Nesse processo, destaque-se a criação do Conselho Estadual de Educação, implantado no ano de 1962, do Centro de Estudos e Pesquisas Educacionais (CEPE) e da Faculdade de Educação (FAED), em 1963, e, ainda, a criação da Universidade para o Desenvolvimento do Estado de Santa Catarina (UDESC), no ano de 1965.

De acordo com Melo (2008), durante o governo de Celso Ramos, foram criadas as instituições educacionais necessárias à modernização da educação catarinense, sendo que a UDESC figura como a instituição de referência no campo educacional, sobretudo porque a ela compete a formação no magistério, considerada fundamental para impulsionar o projeto desenvolvimentista. "A universidade era colo-

15 Vale ressaltar que essa lei manteve as mesmas determinações da Lei Orgânica do Ensino Normal de 1946. Segundo Daros (2005), tal Lei fez parte de um movimento de padronização do sistema educativo nacional; a partir de sua aprovação, as diretrizes para a formação docente seriam centralizadas pelo governo federal. A Lei Orgânica de 1946 desdobrou o ensino normal em dois ciclos: o curso normal regional e o ensino normal. Os cursos normais regionais ou ginásios normais - conforme denominado pela LDB/1961 - teriam como objetivo suprir a carência de professores sem formação para o magistério, sobretudo, nas zonas rurais. cada [...] como o lócus de formação de mentes científicas, capazes de promover a modernização do Estado pelo caminho da racionalidade (MELO, 2008, p. 112). Do mesmo modo, para Valle (1996, p. 73), "a implantação do Conselho Estadual de Educação foi cercada de expectativa de vir a ser, a nível estadual, um órgão impulsor de mudanças educacionais consideradas indispensáveis à concretização do projeto de desenvolvimento econômico".

Ressaltamos que, na década de 1960, há um forte projeto de urbanização, havendo um grande fluxo de migração do campo para as cidades, o país estava se estruturando em muitos aspectos, desde o saneamento básico, a saúde, a educação e os transportes. Neste contexto, os professores em formação nas escolas normais, os mais jovens naquele momento, foram beneficiados por condições educacionais mais favoráveis. Boa parte das docentes que integram a amostra com a qual estamos operando neste texto ingressou no magistério estadual, na década de 1960, com a posse do diploma do ginásio normal, o que não significa que, como temos visto, não encontraram dificuldades para se deslocarem até a escola.

É interesse observar o contraste num tempo no qual os projetos de urbanização estavam em franca expansão, conforme já informado, sendo válido relembrar que, em Santa Catarina, estávamos sob a égide do PLAMEG. Apesar do Estado catarinense exigir uma formação escolar mínima para o exercício do magistério, as precárias condições de acesso a esta formação, neste caso, o acesso físico e o deslocamento, exigiram de boa parte das docentes, e daquelas que figuram como sujeitos neste trabalho mudanças significativas:

Na época já tinha constituído família e residência em Witmarsuns. A E. B. Orlando Bertoli ficava a $35 \mathrm{~km}$ de distância, o que me obrigou a mudar para Presidente Getúlio com a família; trabalhar, estudar e sustentar família de seis pessoas não 
foi fácil com um salário baixo que o governo pagava para o professor. (GORGES, 2010)

É preciso considerar, nesse quadro de reflexão, a oferta de cursos que diplomavam professores normalistas para a rede de ensino do Estado catarinense. No ano de 1966, ${ }^{16}$ havia no Estado 31 instituições particulares que ofereciam o nível colegial (2o ciclo) do ensino normal, contra 14 instituições públicas (dados sobre estes aspectos estão sistematizados na tabela 1, a seguir). Entretanto, se observarmos o número de estabelecimentos que ministravam o ginásio normal (10 ciclo do ensino normal), os números se invertem, são 90 institui- ções públicas de ginásio normal e seis particulares. Esse cenário mostra que o governo estadual atuou priorizando um determinado nível de formação: a de regente de ensino primário, mas revela, sobretudo, os limites da democratização do acesso ao ensino normal de 2 o ciclo, em Santa Catarina. Apesar de prover uma ampliação do número de cargos, de conceder gratificações financeiras ao exercício da função de professor normalista, ${ }^{17}$ o Estado não amplia a rede de escolas públicas que oferecem esse nivel de ensino, permitindo que a formação de professor normalista ocorresse preponderantemente pela via de instituições privadas.

Tabela 1 - estabelecimentos do ensino normal em Santa Catarina - Ano de 1966

\begin{tabular}{|c|c|c|c|}
\hline Município & Estabelecimentos & Rede Pública & Rede Particular \\
\hline \multirow[t]{2}{*}{ Florianópolis } & Colégio Normal & & 1 \\
\hline & Ginásio Normal & 4 & 1 \\
\hline \multirow[t]{2}{*}{ Blumenau } & Colégio Normal & 1 & 3 \\
\hline & Ginásio Normal & 6 & 1 \\
\hline \multirow[t]{2}{*}{ Joinville } & Colégio Normal & 2 & 2 \\
\hline & Ginásio Normal & 6 & \\
\hline \multirow[t]{2}{*}{ Criciúma } & Colégio Normal & & 2 \\
\hline & Ginásio Normal & 9 & 1 \\
\hline \multirow[t]{2}{*}{ Lages } & Colégio Normal & 1 & \\
\hline & Ginásio Normal & 3 & 1 \\
\hline \multirow[t]{2}{*}{ Joaçaba } & Colégio Normal & 1 & 3 \\
\hline & Ginásio Normal & & \\
\hline \multirow[t]{2}{*}{ Chapecó } & Colégio Normal & 2 & \\
\hline & Ginásio Normal & 3 & \\
\hline
\end{tabular}

17 Identificamos duas leis que discorrem sobre a concessão de gratificações financeiras a professores normalistas. A primeira, datada no ano de 1956 (Lei no 1.629), concede uma gratificação mensal no valor de $\mathrm{Cr} \$ 400,00$ (quatrocentos cruzeiros) mensais para os professores normalistas em exercício na zona rural. A segunda é do ano de 1960 (Lei no 2.373) e estabelece que os professores normalistas que se encontrassem no exercício dos cargos de professor, diretor de grupo escolar ou de inspetor escolar, fariam jus a uma gratificação mensal de cr\$1.000,00 (mil cruzeiros).

16 Utilizamos 1966 como referência, por serem esses os dados que temos mapeados. 


\begin{tabular}{|c|c|c|c|}
\hline \multirow[t]{2}{*}{ Porto União } & Colégio Normal & & 3 \\
\hline & Ginásio Normal & 4 & 1 \\
\hline \multirow[t]{2}{*}{ Rio do Sul } & Colégio Normal & 1 & 5 \\
\hline & Ginásio Normal & 8 & \\
\hline \multirow[t]{2}{*}{ Tubarão } & Colégio Normal & 4 & 1 \\
\hline & Ginásio Normal & 11 & 1 \\
\hline \multirow[t]{2}{*}{ Itajaí } & Colégio Normal & & 3 \\
\hline & Ginásio Normal & 4 & \\
\hline \multirow[t]{2}{*}{ Xanxerê } & Colégio Normal & & 1 \\
\hline & Ginásio Normal & 3 & \\
\hline \multirow[t]{2}{*}{ Curitibanos } & Colégio Normal & & 1 \\
\hline & Ginásio Normal & 2 & \\
\hline \multirow[t]{2}{*}{ Mafra } & Colégio Normal & 1 & \\
\hline & Ginásio Normal & 5 & \\
\hline \multirow{2}{*}{$\begin{array}{l}\text { São Miguel } \\
\text { d'Oeste }\end{array}$} & Colégio Normal & & 1 \\
\hline & Ginásio Normal & 4 & \\
\hline \multirow[t]{2}{*}{ Araranguá } & Colégio Normal & 1 & 1 \\
\hline & Ginásio Normal & 4 & \\
\hline \multirow[t]{2}{*}{ Xaxim } & Colégio Normal & 1 & \\
\hline & Ginásio Normal & 1 & \\
\hline \multirow[t]{2}{*}{ Concórdia } & Colégio Normal & & 1 \\
\hline & Ginásio Normal & 3 & \\
\hline \multirow[t]{2}{*}{ Palhoça } & Colégio Normal & 1 & 1 \\
\hline & Ginásio Normal & 7 & \\
\hline \multirow[t]{2}{*}{ Campos Novos } & Colégio Normal & & 2 \\
\hline & Ginásio Normal & 3 & \\
\hline \multirow[t]{2}{*}{ TOTAL } & Colégio Normal & 14 & 31 \\
\hline & Ginásio Normal & 90 & 6 \\
\hline
\end{tabular}

Fonte: Número de estabelecimentos do ensino normal em Santa Catarina, distribuídos conforme os municípios e redes de ensino do ano de 1966. Elaborada a partir da Tabela 4 de Schneider ${ }^{18}$ (2008, p. 84).

18 Para mais informações, consultar: SCHNEIDER, Juliete. A democratização do acesso ao ensino secundário pela expansão do ciclo ginasial normal em Santa Catarina (1946-1969). Dissertação de mestrado apresentada, em 2008, ao Programa de Pós-Graduação em Educação da Universidade Federal de Santa Catarina. 
A partir de 1969, com a aprovação da nova lei do sistema estadual de ensino e, logo em seguida, com a elaboração do primeiro Plano Estadual de Educação (1969a) - para o período de 1969 a 1980 - o discurso legal adquiriu novos contornos. Apesar da lei do sistema estadual de ensino ainda prever a possibilidade de contratação de professores não diplomados, as metas previstas pelo Plano estabelecem que, para o melhor desenvolvimento econômico do Estado catarinense, seria preciso investir na educação, eliminando as categorias de regente de ensino primário e os professores não habilitados, ou professores leigos, nos termos do plano. Percebemos que a indicação do Plano Estadual de Educação (1969a) altera o regime de contratação de professores e passa-se a exigir os titulados.

A partir de 1970, a exigência mínima para ingressar no magistério passa a ser a habilitação específica de segundo grau, ou seja, o ensino pedagógico. ${ }^{19}$ Notamos que aquelas que ingressaram nessa época não possuíam tal formação, o que as levou, nos anos subsequentes, a se engajaram no aperfeiçoamento profissional, a fim de responderem às novas exigências. Observa-se, desde então, um avanço na estruturação hierárquica da carreira do magistério, o que se torna mais evidente com a aprovação do Estatuto do Magistério Público Estadual, de 1975. Este dispositivo legal define a carreira docente e indica possibilidades de ascender a outras categorias funcionais, conforme o nivel de escolaridade do professor. Assim, quanto mais elevado o grau de escolaridade, mais elevada seria a inserção na categoria profissional.

19 O Ensino Normal passa a ser chamado de Ensino Pedagógico, com a aprovação da Lei no 4.394, de 1960, que dispõe sobre o Sistema Estadual de Ensino. 0 Ensino Pedagógico seria ministrado em escolas normais ou institutos de educação, com duração de quatro anos, sendo os dois primeiros comuns aos demais cursos do ciclo médio, mais um ano exclusivamente profissionalizante, seguido de um ano de estágio obrigatório e remunerado.
A estruturação da carreira docente, em termos legais, por vezes não se materializou em condições mais fáceis de acesso à escolarização. Mais uma vez, a questão da distância da escola faz-se presente nos relatos; obter a nova titulação exigida, para alguns, significava retornar aos bancos escolares nos períodos de férias. Casadas, com família constituída e morando em cidades distantes das sedes nas quais era oferecido o ensino pedagógico: “tive que ausentar-me de casa para estudar nas férias, em tempo integral, deixando mulher e filhas no interior de Ituporanga e passar as férias estudando em Rio do Sul" (CARVALHO, 2010). Outro exemplo, "nós deixávamos marido e filhos durante toda a semana, ficávamos instalados em Rio do Sul vindo para casa só aos finais de semana" (RIBEIRO, 2010).

Igualmente, a partir da década de 1970, o professorado engaja-se fortemente na formação de nível superior, fator que decorre não somente das novas exigências governamentais, mas também da expansão das instituições de ensino superior no Estado. Para aqueles que decidem continuar seus estudos, no nivel médio e superior, a fim de ascender na carreira profissional, o percurso é marcado por investimentos pessoais, em termos de tempo dedicado, nos aspectos financeiro e familiar, pois tinham que conciliar a vida de estudante com a vida profissional e familiar. A partir do Ensino Médio, os percursos escolares registrados nas fontes com que estamos trabalhando diferenciam-se consideravelmente: uns optam por abandonar a vida de estudantes, outros continuam seus estudos até a universidade, outros ainda tornam-se especialistas, após frequentarem o primeiro estágio de cursos de pós-graduação. Após ingressarem efetivamente e adquirirem estabilidade, $87 \%$ dos docentes que compõem este estudo avançam na trajetória escolar, obtendo o diploma do ensino normal ou do curso pedagógico; $42 \%$ alcança- 
ram o grau de ensino superior e $21 \%$ concluem algum curso de especialização.

\section{Considerações finais}

Neste artigo, buscamos destacar registros memorialísticos de professoras e professores que atuaram no ensino primário catarinense, com ênfase nos aspectos que retratam seus deslocamentos entre a casa e a escola, enfrentados tanto na condição de alunas como quando já docentes; destacamos também as viagens que fizeram para constituir uma carreira profissional - o que exigia prosseguir nos estudos. Para fazê-lo, operamos a partir de duas questões: como era a trajetória dos professores até o local de trabalho? Do mesmo modo, como eram as condições para quem se mudava, para longe de seu lugar de origem, para lecionar?

O resultado é um conjunto coletivo e seletivo de lembranças, anotações e fatos, sobre viagens e mudanças que mostram um pouco das trajetórias das docentes do ensino primário catarinense, entre as décadas de 1950 a 1980. O cuidado na escrita e na seleção dos materiais aqui registrados foi dirigido principalmente para o entendimento destes relatos como fontes, na busca de contextualizá-los, de forma historiográfica e metódica, em relação a um Brasil e um Estado, o de Santa Catarina, que passava por mudanças na formação e na profissionalização de seus docentes, bem como na implantação de sua infraestrutura.

Ao tratarmos sobre os Percursos e Travessias: do quanto andavam, ressaltamos as distâncias de caminhada até a escola e/ou trabalho. Caminhar por longos trajetos, de seis a trinta quilômetros, em média, até chegar à escola, era comum, dada a falta de infraestrutura e de transportes. Por outro lado, esta realidade registra as condições dadas naquela época, para um profissional iniciante em um país onde poucos tinham acesso a transpor- te público ou mesmo a veículos motorizados. Mais comuns eram os veículos a tração animal, como charretes. Ficam evidentes também as condições materiais de trabalho, como a falta de materiais escolares, livros, uniformes e vestimentas dos estudantes, como calçados, ou ainda de alimentação básica.

No aspecto Viagens: das mudanças de cidade ressalta-se que, já neste período, a profissão é majoritariamente feminina, uma das poucas profissões com abertura ao trabalho e formação para a mulher. Ainda captamos relatos de professoras atuando como domésticas, como forma de complementar a renda ou financiar os estudos. Há também o registro da mudança para a capital e discriminações, por serem filhas de colonos, em um momento em que o trabalho rural era desvalorizado e até ridicularizado.

Considerando um quadro bem mais amplo, Mignot e Gondra (2007) questionam como os modelos pedagógicos viajaram, as estratégias adotadas e seus participantes: a questão que os autores colocam é saber como tais modelos viajaram. "Que estratégias foram adotadas? Quem participou desse jogo de empréstimos e desvios? Em que termos esse diálogo transnacional pode ser percebido? Que tipo de efeito produziu e vem produzindo na definição de um modelo de educação escolar no Brasil?" (MIGNOT; GONDRA, 2007, p. 7). No estudo que aqui apresentamos tratamos o tema a partir de outras lentes, que se deslocam para realidades micro, as quais, certamente, compõem esse horizonte ampliado de que tratam Mignot e Gondra.

No trabalho empírico e nas análises foi possivel narrar, com base em "registros memorialísticos", a partir do ponto de vista das professoras, percursos que fizeram e vivências, como veiculadoras e portadoras de conhecimentos apropriados em escolas normais e institutos de formação. $O$ ajuste das lentes é então di- 
rigido para aqueles que primeiro recebiam as novas influências educacionais - legais, institucionais, formativas - e eram incumbidos de aplicá-las mesmo com todas as dificuldades estruturais encontradas, visto que caberiam às professoras a efetivação - por intermédio da formação de mão de obra qualificada - de um projeto de desenvolvimento econômico que

\section{Referências}

ALVES, Leonora. Questionário concedido ao Projeto Memória Docente.. Florianópolis: Centro de Ciências da Educação, Universidade Federal de Santa Catarina - UFSC, novembro de 2010.

AURAS, Gladys Mary Teive. Modernização econômica e formação do professor em Santa Catarina. Florianópolis: Editora da UFSC, 1998.

Entre o discurso e a prática: um olhar sobre a escola normal catarinense nos anos sessenta. In: SCHEIBE, Leda; DAROS, Maria das Dores. (Orgs.). Formação de professores em Santa Catarina. Florianópolis: NUP/CED/UFSC, 2002. p. 165-178.

BESEN, Danielly Samara. Entre a rigidez e flexibilidade legal: os impactos das exigências de escolaridade sobre a identidade profissional dos professores primários em Santa Catarina (1950-1980). Florianópolis, 2011. Dissertação (Mestrado) - Universidade Federal de Santa Catarina, Centro de Ciências da Educação. Programa de Pós-Graduação em Educação.

BRASIL. Fundo Nacional de Desenvolvimento da Educação. Portaria Ministerial no 955, de 21 de julho de 1994. Tem por objetivo amenizar o problema do acesso dos alunos a escolas. Plano Nacional de Transporte Escolar. Brasília, DF, 2011.

Decreto no 6.768, de 10 de fevereiro de 2009. Disciplina o Programa Caminho da Escola. Brasília, DF, 2009.

Lei no 10.880, de 9 de junho de 2004. Institui o Programa Nacional de Apoio ao Transporte do Escolar - PNATE e o Programa de Apoio aos Sistemas de Ensino para Atendimento à Educação traria a modernização ao Estado catarinense. As viagens que aqui foram narradas contêm diferentes aspectos, dizem muito do lugar de origem das professoras e da luta que travaram para se constituírem professoras. Revelam também que o que caracteriza uma viagem não é apenas a distância percorrida, mas as vicissitudes encontradas no percurso.

de Jovens e Adultos, dispõe sobre o repasse de recursos financeiros do Programa Brasil Alfabetizado, altera o art. 40 da Lei no 9.424, de 24 de dezembro de 1996, e dá outras providências. Brasília, DF: Casa Civil, 2004.

Constituição (1988). Constituição da República Federativa do Brasil. Brasília, DF: Senado Federal: 1988. 292 p.

Lei no 5.692, de 11 de agosto de 1971.

Fixa diretrizes e bases para o ensino de 1으 e 2 으 graus. Brasília, DF: MEC, 1971.

Lei no 4.024, de 20 de dezembro de

1961. Lei de Diretrizes e Bases da

Educação Nacional. Brasília, DF: MEC, 1961.

CANDIDO, Angélica. Questionário concedido ao Projeto Memória Docente. Florianópolis: Centro de Ciências da Educação. Universidade Federal de Santa Catarina - UFSC, novembro de 2010.

CONRADI, Catarina. Questionário concedido ao Projeto Memória Docente. Florianópolis: Centro de Ciências da Educação, Universidade Federal de Santa Catarina - UFSC, novembro de 2010.

CARDOSO, Silmara de Fatima; ZERBINATTI MORAES, Dislane. Viajar é inventar o futuro: narrativas de formação e o ideário educacional brasileiro nos diários e relatório de Anísio Teixeira em viagem à Europa e aos Estados Unidos (1925-1927). Jundiaí, SP: Paco Editorial, 2014.

Carvalho. Ismael. Questionário concedido ao Projeto Memória Docente. Florianópolis: Centro de Ciências da Educação. Universidade Federal de Santa 
Catarina - UFSC, agosto de 2010.

CATANI, Denice. Apresentação. In: CARDOSO, Silmara de Fatima; ZERBINATTI MORAES, Dislane. Viajar é inventar o futuro: narrativas de formação e o ideário educacional brasileiro nos diários e relatório de Anísio Teixeira em viagem à Europa e aos Estados Unidos (1925-1927). Jundiaí, SP: Paco Editorial, 2014. p. 7-12.

CAVALCANTE, Beatriz. Questionário concedido ao Projeto Memória Docente. Florianópolis: Centro de Ciências da Educação. Universidade Federal de Santa Catarina - UFSC, novembro de 2010.

DAROS, Maria das Dores. Formação de professores em Santa Catarina: breves considerações sobre sua história. In: DAROS, Maria das Dores; DANIEL, Leziany Silveira; SILVA, Ana Claudia da. (Orgs.) Fontes históricas: contribuições para o estudo de professores catarinenses (1883-1946). Florianópolis: NUP/ CED/UFSC, 2005. p. 11-22.

FERBER, Luiza Pinheiro. Um mal necessário: as escolas isoladas no projeto republicano (Santa Catarina, 1911-1928). Florianópolis: 2015. 155 f. Dissertação (Mestrado em Educação) - Centro de Ciências Humanas e da Educação, Programa de Pós-Graduação em Educação, Universidade do Estado de Santa Catarina, Florianópolis, 2015.

FIORI, Neide de Almeida. Apresentação. In: GASPAR DA SILVA, VERA LUCIA; SHUEROFF, Dilce. (Orgs.). Memória docente: Histórias de professores catarinenses (1890-1950). Florianópolis: UDESC Editora, 2010. p. $9-24$.

FLUSSER, Dilma. Questionário concedido ao Projeto Memória Docente. Florianópolis: Centro de Ciências da Educação, Universidade Federal de Santa Catarina - UFSC, novembro de 2010.

GASPAR da SILVA, Vera Lucia. "Profissão: Professora!" In: CAMPOS, Maria Christina Siqueira de Souza; GASPAR DA SILVA, Vera Lúcia. (Orgs.). Feminização do magistério: vestígios do passado que marcam o presente. Bragança Paulista, SP: Editora da Universidade São Francisco, 2002. p. 95-121.

Gomes, Irene. Questionário concedido ao Projeto Memória Docente. Florianópolis: Centro de Ciências da Educação, Universidade Federal de Santa Catarina - UFSC, novembro de 2010.

GOrges, Helena. Questionário concedido ao Projeto Memória Docente. Florianópolis: Centro de Ciências da Educação, Universidade Federal de Santa Catarina - UFSC, novembro de 2010.

GUIMARÃES, Lídia. Questionário concedido ao Projeto Memória Docente. Florianópolis: Centro de Ciências da Educação, Universidade Federal de Santa Catarina - UFSC, outubro de 2010.

IBGE. INSTITUTO BRASILEIRO DE GEOGRAFIA E ESTATísTICA. Anuários Estatísticos do Brasil. Base de dados. Brasília, DF: IBGE, 2017. Disponível em: <http:/ / seculoxx.ibge.gov.br/home-seculo-xx>. Acesso em: 18 mar. 2017.

KINCHESCl, Ana Paula. É preciso fazer por merecer: representações docentes sobre o "ser aluno" (Santa Catarina, 1940-1970). 2015. 226 f. Dissertação (Mestrado em Educação) - Centro de Ciências Humanas e da Educação, Programa de Pós-Graduação em Educação, Universidade do Estado de Santa Catarina, Florianópolis, 2015.

KONS, Ester. Questionário concedido ao Projeto Memória Docente. Florianópolis: Centro de Ciências da Educação, Universidade Federal de Santa Catarina - UFSC, novembro de 2010.

MARQUES, Sônia. Questionário concedido ao Projeto Memória Docente. Florianópolis: Centro de Ciências da Educação, Universidade Federal de Santa Catarina - UFSC, novembro de 2010.

MELO, Marilandês Mól Ribeiro de. Sílvio Coelho dos Santos - um intelectual moderno no Centro de Estudos e Pesquisas Educacionais (CEPE) - SC: pertencimento, missão social e educação para a formação/modernização (1960/1970). 2008. 167 f. Dissertação (Mestrado em Educação) - Centro de Ciências da Educação, Programa de Pós-Graduação em Educação, Universidade Federal de Santa Catarina, Florianópolis, 2008.

Não sei se valeu a pena ter sido professor, mas foi uma vida: convergências e divergências entre o projeto de modernização do governo catarinense e o corpo docente da Rede Estadual de En- 
sino de Santa Catarina (década de 1960). 2014. 391 f. Tese (Doutorado em Educação) - Centro de Ciências da Educação, Programa de Pós-Graduação em Educação, Universidade Federal de Santa Catarina, Florianópolis, 2014.

MEC/FNDE. FUNDO NACIONAL DE DESENVOLVIMENTO DA EDUCAÇÃO. Apresentação. Brasília, DF: MEC, 2017. Disponivel em: <http://www.fnde.gov.br/ programas/transporte-escolar/transporte-escolar -apresentacao>. Acesso em: 19 mar. 2017.

Meyer, Florentina. Questionário concedido ao Projeto Memória Docente. Florianópolis: Centro de Ciências da Educação, Universidade Federal de Santa Catarina - UFSC, novembro de 2010.

MIGNOT, Ana Chrystina Venancio; GONDRA José Gonçalves. (Orgs.). viagens pedagógicas. São Paulo: Cortez, 2007.

MONTEIRO, Vilma. Questionário concedido ao Projeto Memória Docente. Florianópolis: Centro de Ciências da Educação, Universidade Federal de Santa Catarina - UFSC, novembro de 2010.

Nunes, TEREZINHA. Questionário concedido ao Projeto Memória Docente. Florianópolis: Centro de Ciências da Educação, Universidade Federal de Santa Catarina - UFSC, novembro de 2010.

PEREIRA, Elisa. Questionário concedido ao Projeto Memória Docente. Florianópolis: Centro de Ciências da Educação, Universidade Federal de Santa Catarina - UFSC, novembro de 2010.

PREFEITURA MUNICIPAL DE RIO DO OESTE. Rio do Oeste, história em imagens. 2017. Disponível em: <http://www.riodooeste.com.br/historia/?id=institu/album\&p=1\&r=2\&i=6>. Acesso em: 18 mar. 2017.

PROENÇA, Maria. Questionário concedido ao Projeto Memória Docente. Florianópolis: Centro de Ciências da Educação, Universidade Federal de Santa Catarina - UFSC, novembro de 2011.

RECH, Zilma. Questionário concedido ao Projeto Memória Docente. Florianópolis: Centro de Ciências da Educação, Universidade Federal de Santa Catarina - UFSC, novembro de 2010.

RIBEIRO, Ângela. Questionário concedido ao Proje- to Memória Docente. Florianópolis: Centro de Ciências da Educação, Universidade Federal de Santa Catarina - UFSC, novembro de 2010.

Rios, Margarida. Questionário concedido ao Projeto Memória Docente. Florianópolis: Centro de Ciências da Educação, Universidade Federal de Santa Catarina - UFSC, novembro de 2010.

ROSA, Glória. Questionário concedido ao Projeto Memória Docente. Florianópolis: Centro de Ciências da Educação, Universidade Federal de Santa Catarina - UFSC, outubro de 2010.

SANTA CATARINA. Lei no 5.684, de 9 de maio de 1980. Dispõe sobre o serviço público de transporte rodoviário intermunicipal de passageiros e dá outras providências. Florianópolis, SC, 1980.

\section{Plano Estadual de Educação,} 1969/1980. Florianópolis: SEE, 1969a.

Lei no 4.394, de 20 de novembro de 1969. Dispõe sobre o sistema estadual de ensino. Florianópolis, SC: 1969b.

Lei no 3.191, de 06 de maio de 1963. Dispõe sobre o Sistema Estadual de Ensino. Florianópolis, SC: 1963.

Lei no 2.373, de 15 de junho de 1960. Concede gratificação a professor normalista. Florianópolis, SC, 1960.

GOVERNADOR, 1961-1966 (Celso Ramos). Plano de Metas do Governo Celso Ramos. Florianópolis, SC: 1961.

. Lei no 1.629, de 22 de dezembro de 1956. Dispõe sobre o reajustamento do quadro de funcionários públicos civis do poder executivo, concede aumento de vencimentos e salários a funcionários civis e militares, a extranumerário mensalistas e a inativos e dá outras providências. Florianópolis, SC, 1956.

Sardá, Zenir. Questionário concedido ao Projeto Memória Docente. Florianópolis: Centro de Ciências da Educação, Universidade Federal de Santa Catarina - UFSC, novembro de 2010.

SCHEIBE, Leda; DAROS, Maria das Dores. Formação 
de professores em Santa Catarina. Florianópolis: NUP/CED/UFSC, 2002.

SCHNEIDER, Juliete. A democratização do acesso ao ensino secundário pela expansão do ciclo ginasial normal em Santa Catarina (1946-1969). 2008. $171 \mathrm{f}$. Dissertação (Mestrado em Educação) - Centro de Ciências da Educação, Programa de Pós-Graduação em Educação, Universidade Federal de Santa Catarina, Florianópolis, 2008.

SENS, Joana. Questionário concedido ao Projeto Memória Docente. Florianópolis: Centro de Ciências da Educação. Universidade Federal de Santa Catarina - UFSC, novembro de 2010.

Silveira, Úrsula. Questionário concedido ao Projeto
Memória Docente. Florianópolis: Centro de Ciências da Educação. Universidade Federal de Santa Catarina - UFSC, novembro de 2010.

STEPHANOU, Maria; BASTOS, Maria Helena Camara. História, memória e história da educação. In: STEPHANOU, Maria; BASTOS, Maria Helena Camara. (Orgs.). História e memórias da educação no Brasil. 4. ed. Petrópolis, /RJ: Vozes, 2011. (Século XX, 3).

VALLE, Ione Ribeiro. Burocratização da educação: um estudo sobre o Conselho Estadual de Educação do Estado de Santa Catarina. Florianópolis: Ed. da UFSC, 1996.

Recebido em: 20.03.2017

Aprovado em: 24.06.2017

Danielly Samara Besen é Mestra em Educação / UFSC, Doutoranda em Educação UDESC. Observatório de Práticas Escolares - OPE / Projeto de Pesquisa: Objetos em Viagem: Provimento material da escola primária em países ibero-americanos (1870 - 1920). Grupo de Pesquisa Ensino e Formação de Educadores em Santa Catarina - GPFESC. e-mail: daniellybesen@gmail.com

Rua Desembargador Urbano Salles, 111 Apto. 804 Bloco A. Centro - Florianópolis/SC - CEP: 88015-430

Telefone: (48) 98822-0625

Vera Lucia Gaspar da Silva é Doutora em Educação pela USP. Professora Associada da Faculdade de Educação da Universidade do Estado de Santa Catarina. Observatório de Práticas Escolares - OPE / Projeto de Pesquisa: Objetos em Viagem: Provimento material da escola primária em países ibero-americanos (1870 - 1920). Grupo de Pesquisa Ensino e Formação de Educadores em Santa Catarina - GPFESC. e-mail: vera.gaspar.udesc@gmail.com

Rua Lauro Linhares, 657 - Bloco A / Apto 302, Trindade - 88.036-001 - Florianópolis - SC

Telefone: (48) 3232-2225 e (48) 99998-0148

Emerson Correia da Silva é Doutor em Educação pela UNESP, Professor Assistente da Faculdade Cesusc. Grupo de pesquisa: Gestão e Tecnologia no Ensino Superior - GeTES. e-mail: emerson.correia.silva@gmail.com

Faculdade Cesusc

Rod. José Carlos Daux (SC401), 9301 - Km 10 - Santo Antônio de Lisboa - 88.050-001 - Florianópolis - SC

Telefones: (48) 3239-2600 (48) 99190-0328 